\title{
The classification and registration of bone dysplasias
}

\author{
N. R. BUTLER \\ M.D., F.R.C.P., D.C.H. \\ Department of Child Health, University of Bristol
}

FOR centuries skeletal deformities have fascinated many civilizations, for example, the Egyptian god Ptah was depicted as a short-limbed dwarf and metabolic bone disorders were recognized in early Christian times. Dwarfs with achondroplasia were court favourites in the mighty days of Spain, as portrayed by Velasquez in 'Las Maneñas' now in the Prado in Madrid. The sixty or so persons at this symposium, representing twelve different disciplines within the medical, dental and veterinary professions, show what great modern interest exists in this intriguing group of disorders.

In recent years, attempts to classify bone dysplasias have been more prolific than enduring; and not until radiology became ubiquitous was any rational approach possible to their classificationstarting perhaps with that of Jansen (1934), with further landmarks by Fairbank (1951), Brailsford (1953), Lamy and Maroteaux (1961), Rubin (1964) and more recently by Spranger, Langer and Wiedemann (1974). Depending perhaps upon the genetics or environment of the 'architect', these classifying systems had either an anatomical, radiological, aetiological or histopathological basis, or sometimes a healthy heterogeneity on which perhaps continued survival depends. Attempting to introduce more logic and fewer eponyms, some years ago continental centres such as Paris (Maroteaux), Cracow (Kozlowski) and Kiel (then Spranger) decided to form multi-disciplinary registries and now we have similar active British organizations at Leeds, Cardiff and Bristol.

In 1969 the European Society of Paediatric Radiology (ESPR) adopted a classification and, hoping to eliminate confusing and sometimes unsure eponymous titles, and to promote a standard terminology this was published by McKusick and Scott in 1971.

The first and larger of the two major sub-divisions of this classification consists of osseous diseases of unknown pathogenesis, which can be further separated into the osteochondrodysplasias, the dysostoses and the osteolyses. The osteo-chondrodysplasias can again be sub-divided into three types. The first comprises defects of growth of tubular bones and/or the spine: these can be sub-divided into those manifest at birth, e.g. achondroplasia, chondrodysplasia punctata, and those presenting in later life such as the metaphyseal chondrodysplasias. Next, there are disorders with disorganized development of cartilage and/or fibrous tissue-enchondromatosis, multiple exostoses, etc. Lastly, in this group are abnormalities of bone density, of cortical and metaphyseal structure and/or remodelling, e.g. osteopetrosis, diaphyseal dysplasias and osteogenesis imperfecta.

The dysostoses have likewise three sub-groups: (1) those with cranio-facial involvement, Apert, Treacher-Collins and Crouzon syndromes; (2) those with axial abnormalities, e.g. Klippel-Feil, Sprenger; (3) those predominantly involving the extremities such as hemimelia, polydactyly, etc.

The second and smaller major sub-division of the ESPR classification comprises the intrinsic diseases of bone with known pathogenesis, also with three subgroups. Firstly, chromosomal disorders, secondly, the primary metabolic diseases including errors of calcium and phosphate metabolism, of amino-acids, the mucopolysaccharidoses and lipidoses. Thirdly, there are bone diseases secondary to disturbances of extra-skeletal systems.

Finally, and really belonging to the idiopathic group, are primary disorders of bone growth as a whole, including the various dwarfism syndromes, such as Russel-Silver, Cornelia de Lange, Marfan, progeria and leprechaunism.

What is the value of bone dysplasia registries? The Bristol Registry was founded 7 years ago on the enthusiasm and initiative of Dr Ian Gordon, with accommodation in the Royal Hospital for Sick Children and a part-time secretary. Meetings have continued to be held at 2-monthly intervals when 
usually three new patients are presented, so that to date some eighty or so cases have been classified by the panel. Interest has steadily mounted, one major value being the collaboration of the multi-disciplinary panel and assessment of patients by experts in radiodiagnosis, paediatrics, genetics and orthopaedics, with valuable and regular support from fields such as chemical pathology, morbid anatomy, dentistry, psychiatry, and others.

Success depends not only on first-class radiology, but also upon having a complete 'work-up' for each patient well before panel discussion. This includes a past and family history, a full physical examination and recording of height, weight, growth and other vital measurements and where indicated reports of special investigations, e.g. dental, dermatoglyphic, chromosomal, etc. Complete biochemical studies are performed whenever possible, including routine screening for metabolic disorders. All this information is recorded on a pro-forma and transferred to a punch card system for computer analysis. A clinical report is issued in respect of each patient, with genetic, orthopaedic, prognostic and other recommendations. Cases may be reviewed at regular intervals so that revision of classification may take place if appropriate.
To conclude, the usefulness of the registry can be summed up as being educational, in respect of the interaction of all participating disciplines concerned with patient management; catalytic in generating further study and practical in providing diagnostic and prognostic information and in furnishing a basis for future research.

\section{References}

BRAILSFORD. J.F. (1953) Radiology of Bones and Joints. 5th edition. Churchill, London.

FaIRbank, H.A.T. (1951) An Atlas of General Affections of the Skeleton. Livingstone, Edinburgh.

JANSEN, M. (1934) Über atypische Chondrodystrophie (Achondroplasie) und über eine noch nicht beschriebene angeborene Wachstumsstörung des Knochensystems. Zeitschrift für orthopädische Chirurgie, einschliesslich der Heilgymnastik und Massage, 61, 253.

Lamy, M. \& Maroteaux, P. (1961) Les Chondrodystrophies Génétypiques. Paris, L'expansion scientifique française.

McKusick, V.A. \& ScotT, C.I. (1971) A nomenclature for constitutional disorders of bone. Journal of Bone and Joint Surgery, 53A, 978.

RubIN, P. (1964) Dynamic Classification of Bone Dysplasias. Year Book Medical Publishers, Chicago.

SpRANGer, J.W., LANGer, L.O. \& WiedemanN, H-R. (1974) Bone Dysplasias: An Atlas of Constitutional Disorders of Skeletal Development. W. B. Saunders Co., Philadelphia. 